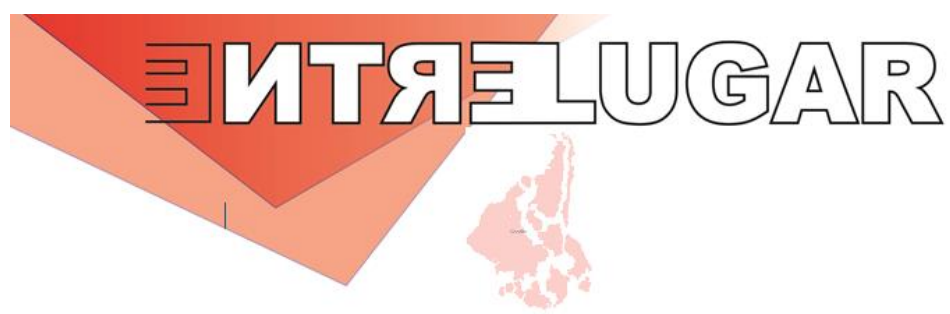

\title{
TRANSESPAÇO DA FLORESTA: A COSMOPOLÍTICA YANOMAMI ATRAVÉS DE UM FILME
}

\author{
THE FOREST TRANSPACE: THE YANOMAMI COSMOPOLITCS BY MEANS \\ OF A FILM
}

\section{TRANSESPACIO DE LA SELVA: LA COSMOPOLÍTICA YANOMAMI A TRAVÉS DE UNA PELÍCULA}

\author{
Helena Augusta da Silva Gomes \\ outrahelena@gmail.com
}

Universidade Federal de Minas Gerais ${ }^{3}$

\begin{abstract}
RESUMO: O presente artigo analisa o filme "Urihi Haromatipë - Curadores da TerraFloresta" (BRA, 2014), do diretor indígena Morzaniel Iramari, realizado entre os Yanomami, com a colaboração de realizadores não-indígenas. Tal filme é pensado mediante o conceito de cosmopolítica, como é trabalhado na antropologia. $\mathrm{O}$ artigo busca construir a ideia de um transespaço da cena, construído mediante a convergência entre os discursos interétnicos dos indígenas, — que apontam para a manutenção da floresta e de seu território - e as relações entre eles e outros seres que participam da cena. Para tanto, são consideradas as formas de organização da mise-en-scène do filme, assim como os discursos dos xamãs dirigidos aos brancos, por meio dela, que se envolve, de diferentes formas, com o território ocupado.
\end{abstract}

Palavras-chaves: Imagem; Cosmopolítica; Território; Cinema indígena; Cultura.

ABSTRACT: The present article discuss the film "Urihi Haromatipë-Os curadores da terra-floresta", directed by the indigenous director Morzaniel Iramari, and shot among the Yanomami people, with the collaboration of non-indigenous creators. The movie has been analyzed with the concept of cosmopolitics, as it is crafted in the field of anthropology. The article aims to build the idea of a transespace of the scene, through the convergence between the interethnic discourses of the indigenous people - which claims for the maintenance of the forest and the indigenous territory - and the relationship between them and other beings who participate in the scene. For this purpose, it is considered the film's mise-en-scène, as well as the speeches of the shamans addressed to the white people, which gets involved, in many different ways, with the occupied territory.

Keywords: Image; Cosmopolitics; Territory, Indigenous cinema, Culture.

\footnotetext{
${ }^{3}$ Bolsista CAPES/BRASIL. INCT - Instituto da Democracia e da Democratização da Comunicação. Doutoranda em Geografia pelo PPGGeo/UFMG
} 
RESUMEN: Este artículo analiza la película "Urihi Haromatipë - Curadores da TerraFloresta" (BRA, 2014), del director indígena Morzaniel Iramari, realizada entre los yanomami, con la colaboración de cineastas no-indígenas. Tal película es pensada a través del concepto de cosmopolítica, como esta es trabajada em el campo antropológico. El artículo busca construir la idea de un transespacio de la escena, hecho a través de la convergencia entre los discursos interétnicos de los pueblos indígenas, que apuntan al mantenimiento de la selva y su territorio, y las relaciones entre ellos y otros seres que participan en la escena. Para esto, se consideran las formas de organización de la miseen-scène de la película, así como los discursos de los shamanes dirigidos a los blancos, a través de la película, que se involucran, de diferentes maneras, con el territorio ocupado.

Palavras clave: Image; Cosmopolítica; Territorio; Cine indígena; Cultura.

\section{INTRODUÇÃO}

Se, convencionalmente, o espaço social foi considerado a partir de relações interpessoais que acontecem em repartições dimensionais diversas, os territórios, os lugares e as regiões foram considerados como recortes de mundo concebidos a partir de suas medidas e análises possíveis, a partir, em alguns casos, de sua reprodução, compreendida na produção e no consumo de bens e das culturas espacializadas nas sociedades contemporâneas. Entretanto, é possível, igualmente, conceber o espaço, assim como suas formas manifestas, territorializadas, lugarizadas, para além de unidades socioespaciais cartografadas de modo tradicional, leia-se, segundo uma tradição ocidental, que pode deixar subsumidos alguns aspectos do mundo animado por dimensões diversas de vida que nele pode existir. O espaço aparece, assim, como ambientes vividos, sentidos e percebidos em uma cotidianidade compartilhada, que se faz a partir de inscrições de objetos e corpos e seus trânsitos, compondo territórios, fronteiras e limites.

Pensemos o espaço e a cena de um filme: eles são, antes de tudo, entendidos para além de uma junção entre o local da experiência e a mediação envolvida nas relações entre os sujeitos e os seres em coabitação. Aqui consideremos a incomensurabilidade do espaço; o espaço para onde convergem experiências e de onde elas podem extrapolar, devolvendo ao mundo de onde emergiram suas possíveis reelaborações. Um certo espaço, recortado em cena, é constituído nas coincidências dos vários atravessamentos possíveis 


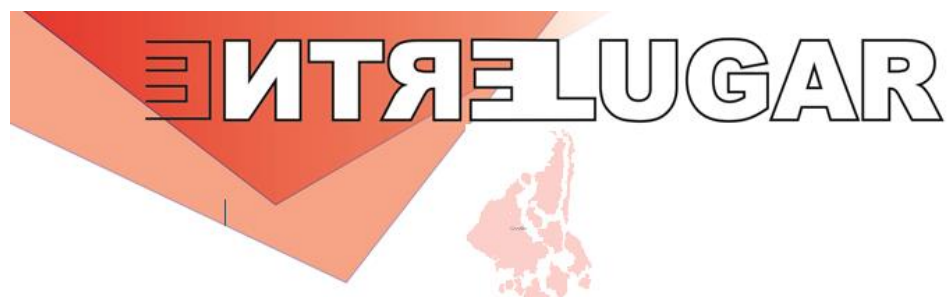

no espaço do filme, como chão de mundo vivido e partilhado, através das fisicalidades dos ambientes e dos trânsitos das agências invisíveis, ou seja, das implicações do cosmos.

Seria possível ao filme documentário não somente registrar uma dimensão do espaço, mas produzir uma certa forma dele? Pode ele ser um tradutor de espaço, como sugere Renata Marquez (2006), ou ser concebido como uma manifestação dele, em sua transformação a partir das relações por e para ele estabelecidas? Os liames que unem possíveis respostas a estas questões encontram-se, em parte, na concepção do espaço como produto de relações. ${ }^{4}$

A imagem é formada como um espaço de coabitação, sendo tributária de ações para que o filme se faça enquanto uma escrita conjunta. Se um certo espaço-lugar depende do local para existir, os transespaços em cena são concebidos como coexistentes com os locais fílmicos, com os corpos que nele performam e que dele fazem chão de manifestação. A partir das relações instituintes da cena — esta estruturada a partir de alteridades ali presentes, visíveis ou não — produzem-se novas instâncias abertas, múltiplas, atravessadas.

\section{TERRITÓRIO EM CENA}

Uma possível interpelação como ponto de partida: “Urihi Haromatipë Curadores Da Terra-Floresta", de Morzaniel Iramari. O filme, ${ }^{5}$ realizado entre os Yanomami, se construiu a partir de encontros entre xamãs na aldeia Watoriki, no estado brasileiro de Roraima. Considerado enquanto "forma que pensa", conforme o desenvolvimento de André Brasil (2016), ao refletir sobre como o cinema pode assumir aspectos de um modo xamânico de conhecimento e tradução, ${ }^{6}$ o filme é trabalhado, aqui, mediante o atravessamento de traços de um gesto cosmopolítico em sua tessitura mesma,

\footnotetext{
4 Tal concepção, apesar de parecer óbvia, precisa ser relembrada, dada as conceituações simplificadoras presentes em parte do pensamento científico moderno, por exemplo, dentre alguns pensadores que o trabalham a partir de um conhecimento socioespacial limitado às fisicalidades dos ambientes e à dimensão visível, aparente, dos fenômenos. Sigo, no entanto, o pensamento de Milton Santos (1997), que concebe o espaço social como formado por fixos e fluxos, que o atravessam e o modificam ao longo do tempo.

${ }^{5}$ Urihi Haromatipe foi realizado subsequentemente ao filme "Xapiri", elaborado a partir dos dois encontros de xamãs na aldeia, realizados entre 2011 e 2012, na aldeia citada.

${ }^{6}$ Resguardando todas relações implicadas nesse cinema, dos processos de coautoria presentes em tais filmes, como pondera o autor.
} 


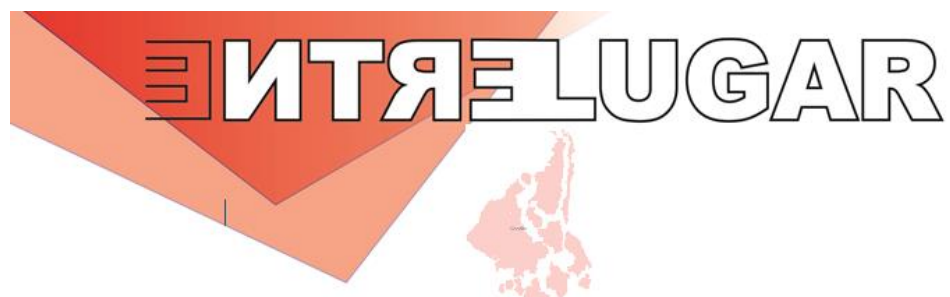

mediante a convergência entre os discursos interétnicos, os cantos xamânicos, as agências invisíveis e as palavras, inteligíveis ou não, que apontam para o alerta sobre os cuidados que devemos ter para com a terra-floresta e para as práticas xamânicas que não podem ser dispersas:

O discurso político indígena das últimas décadas se funda em um duplo enraizamento simbólico: numa auto-objetivação através das categorias brancas da etnificação ("território", "cultura", "meio ambiente"). A partir do momento em que entram na arena política interétnica, os índios, não sem perplexidade, têm que se debater contra esse duplo imaginário da Natureza de seus interlocutores brancos. Para eles, não existe hoje discurso político realmente eficiente fora desse registro. Só nele podem rebater a negação produtivista de seus adversários e, ao mesmo tempo, se esforçar em traduzir sua própria alteridade nos termos do indigenismo ambientalista de seus defensores ideologicamente simpático, embora culturalmente equivocado (ALBERT, 1995, p. 4).

A mediação pela imagem: formação de um entre? A imagem existe por alguém e para alguém, a partir do olhar; é, dessa forma, uma maneira de estar junto. As imagens existem e operam, de forma inevitável, entre sujeitos:

É porque a imagem não é nem uma coisa nem uma pessoa que ela opera entre sujeitos enquanto operadora de uma relação, sem usufruir, ela própria, de nenhum estatuto ontológico nem teológico, e, sobretudo, sem se reduzir à sua materialidade (MONDZAIN, 2011, p. 108-109, grifos meus.)

A imagem é, seguindo o pensamento de Marie-José Mondzain (2011), constituída por dimensões visíveis e invisíveis. Ela será, sempre, uma formação entre o que vê e o que se poderia ver, o que se imagina a partir de sua apresentação visível. Tal possibilidade define sua vocação política, segundo o pensamento da autora, que é, aqui, estendido no sentido de um devir cosmopolítico, ainda que Mondzain não recorra ao termo. Seguindo tais ideias, apresentadas pela filósofa francesa, Rodrigo Silva (2011) pensa a imagem não apenas como um objeto, mas como uma "operadora de passagem", que estabelece uma ligação entre dois regimes ontológicos.

Refletir acerca de "Curadores da floresta" envolve pensar em Davi Kopenawa e seu engajamento político enquanto uma liderança indígena, assim como um importante xamã Yanomami, e implica, igualmente, uma aproximação, ainda que precária nesse momento, sobre a ideia de Urihi, compreendido como um espaço sócio-cosmológico ${ }^{7}$ que ultrapassa, em larga medida, a concepção de terra, apresentada como sua tradução.

\footnotetext{
${ }^{7}$ Segundo as ideias apresentadas por Eduardo Viveiros de Castro (2004).
} 


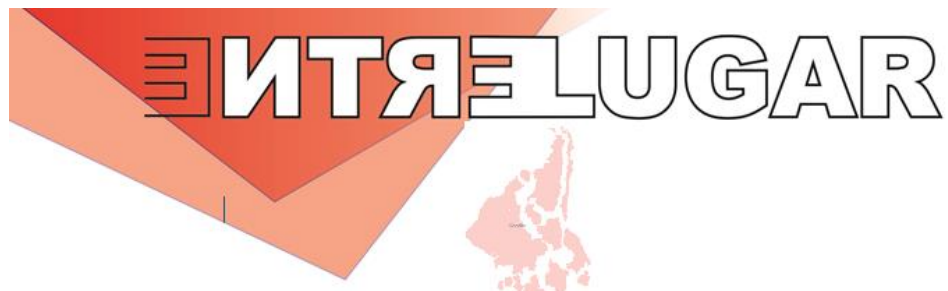

Na seminal obra "A queda do céu — Palavras de um xamã Yanomami” (2016), escrita conjuntamente por Davi Kopenawa e o antropólogo Bruce Albert, conhecemos o discurso localizado do xamã, que fala para um auditório amplo (todo o mundo branco, ocidental) a partir de seu papel de mediador, um tradutor de mundos em dois sentidos, como um xamã Yanomami, um sujeito transespecífico, que administra as “perspectivas cruzadas" (VIVEIROS DE CASTRO, 2004). Esse papel de operador de passagem entre mundos, entre humanos e espíritos, e, igualmente, se faz também no nível da interlocução entre brancos e índios.

Por Kopenawa, Urihi é apresentada já a partir de sua constituição enquanto entidade espacial que abriga seres de diversas naturezas, dentre eles os xapiri, os espíritos habitantes da floresta:

Os xapiri nunca se deslocam na floresta como nós. Descem até nós por caminhos resplandecentes, cobertos de penugem branca, tão fina quanto os fios das teias de aranha ware koxiki que flutuam no ar. Esses caminhos se ramificam para todos os lados, como os que saem de nossas casas. Sua rede cobre toda a nossa floresta. Eles se bifurcam, se cruzam e até se superpõem, para muito além dela, por toda a vasta terra a que chamamos urihi a pree ou urihi a pata, e que os brancos chamam de mundo inteiro (ALBERT e KOPENAWA, 2010, p. 115-116).

A concepção de mundo declarada por Kopenawa, assim como sua visão sobre a floresta e a condição humana, interpela todos os esforços de um "diálogo multicultural"8 que se colocam na cena política-científica contemporânea, apontando, de imediato, para as leituras cosmopolíticas apresentadas como potências, e acaba sendo uma provocação à ciência, à ideia de mundo inteiro, assim como dos recortes, esquadrinhados pelo pensamento moderno, que cinde sujeito e objeto. Segundo a leitura de Stutzman (2013), tal concepção estrutura o discurso político de Kopenawa, que a localiza como uma prática xamânica e uma profecia, já que a fala do xamã se organiza a partir de um ponto de vista, que está no cerne da cosmologia Yanomami, e que inclui os outros pontos de vista, ou

\footnotetext{
${ }^{8}$ Boaventura de Sousa Santos, autor dessa expressão, é um dos questionadores das possibilidades e condições de tal "diálogo", ao pensar as aberturas da monocultura do conhecimento científico moderno e seu necessário contato com saberes e culturas que foram silenciadas e suas formas de ver e conhecer o mundo tornadas inauditas (SANTOS, 2000).
} 


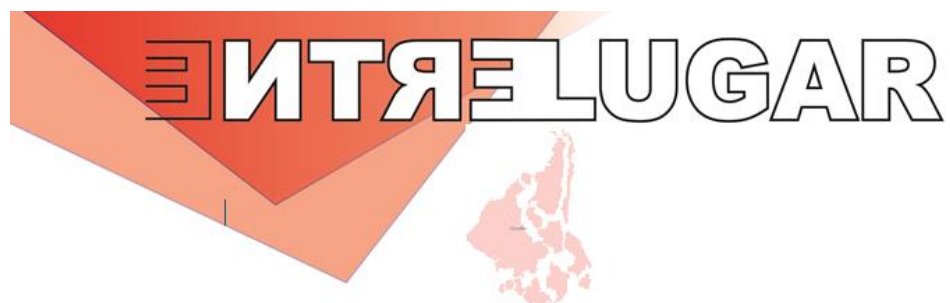

seja, a dos outros seres da floresta dotados de uma imagem essencial (tupë), aos quais os xamãs, como mediadores de mundos, podem “fazer descer". 9

A concepção da terra floresta de Kopenawa, incorporando uma sociocosmologia - na consideração da floresta como um espaço vivo e animado pela expressão de todos os seus seres, dotados de intencionalidade e agenciamento, respeitando suas perspectivas, e sua morada - prescinde do pensamento dicotômico moderno, ao considerar todos os seres habitantes da floresta, humanos, animais e espíritos ${ }^{10}$. Seu discurso se localiza e se compreende, estrategicamente, ao que parece, para além tanto de uma natureza transcendental, como de uma natureza reificada, um recurso natural. Todo um cosmos é considerado e é o encontro desses universos, pensados em sua essencial coexistência e como garantia da existência do mundo, e é precisamente isso que caracteriza a singularidade da fala de Kopenawa. ${ }^{11}$

Em texto publicado anteriormente ao livro, mas já tendo somado longos anos de convívio entre os Yanomami, - relação do qual se desdobraria uma especial amizade com Kopenawa -, Bruce Albert, apresentando a crítica xamânica da economia política da natureza, diz como a localização tradutora do discurso de Kopenawa fundaria um novo discurso político indígena, discurso esse que envolve negociações interétnicas, pelo trabalho do xamã e seu encontro ao discurso ambientalista contemporâneo, que, pelo seu lado, quer assimilar perspectivas diferentes sobre os povos da floresta. O livro "A queda do céu", visto pelo antropólogo como um "manifesto cosmopolítico", ancorado numa

\footnotetext{
9 Bruce Albert (1995, p. 10) anota que a importância de se proteger a floresta reside exatamente na consideração desses coabitantes da terra floresta, dos espíritos auxiliares que são os “[...] responsáveis pela ordem cosmológica dos fenômenos ecológicos meteorológicos (migração da caça, fertilidade de plantas silvestres, controle da chuva, alternância das estações...) ".

10 Tal pensamento antecipa essas lições que agora o ecologismo se debruça e, com dificuldades, tenta assimilar, como pensa Viveiros de Castro. Segundo o antropólogo, o ameríndio não pensa na natureza, pensa nas humanidades, nos seres, nas pessoas humanos (animais e humanos) como habitantes da floresta, coabitação em seu sentido mais profundo e por isso mais incompreensível ao olhar ocidental. A condição original comum aos humanos e animais não é a animalidade, mas a humanidade. Primeiro eram todos humanos, depois vem o animismo de alguns. Ao contrário dos modernos, que partem de todos animais, e o humano se humanizando, diferenciando, se tornando soberano sobre os demais.

${ }^{11} \mathrm{O}$ pensamento perspectivista ameríndio, tal como apresentado por Viveiros de Castro (2004), entende os outros seres da floresta em sua condição humana, não como espécie, mas como sujeitos que fundam essa condição, seres dotados de subjetividade. A condição social de pessoa é considerada a partir do seu poder de ponto de vista. Tal concepção ultrapassada a visão moderna de humanidade/animalidade.
} 


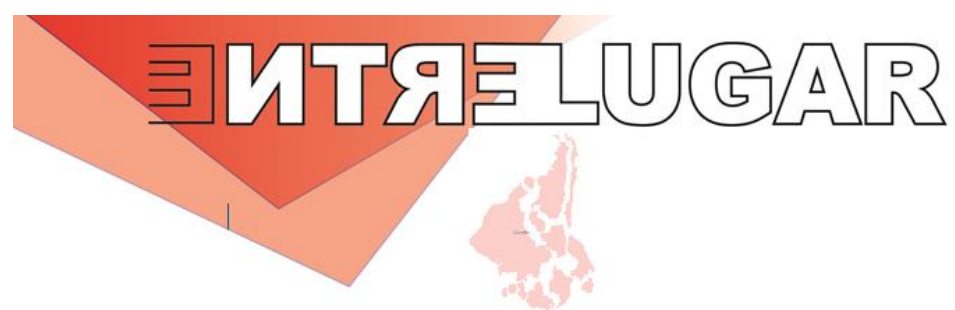

prática xamânica, é interpretado por Renato Sztutman segundo suas múltiplas características, como:

Discurso cosmopolítico que é também discurso profético, leitura de acontecimentos históricos pelo viés da mitologia e da cosmologia. Discurso cosmopolítico que teria, por fim, caráter de diplomacia - isto é, constitui-se no trânsito entre mundos e no uso preciso e estratégico da linguagem (SZTUTMAN, 2013, p. 3-4).

A ideia de diplomacia trazida por pelo autor para o campo antropológico, de modo a realizar uma leitura da obra de Albert e Kopenawa, é inspirada nas ideias de Isabelle Stengens (2011), quando a filósofa desenvolve sua "proposição cosmopolítica". Para ela, Sztutman (2013) diz, o diplomata é um mediador entre mundos não hierárquicos, que assume uma negociação a partir do que assume e considera acerca de outros saberes, diferente do papel assumido pelo expert, dono da "voz competente" que se considera fonte de uma verdade garantida, unilateralmente produzida.

Se Stengers (2011) aponta a cosmopolítica como uma desaceleração em relação à política, o livro pode ser entendido segundo esse pensamento; sua robusteza, em tamanho e densidade, assume todos os acontecimentos como importantes. As palavras gravadas fazem durar, fazem sentir um saber, uma prática, uma práxis que, levou muitos anos para ser gestada, a partir do envolvimento de Bruce Albert e sua relação com Kopenawa. Desacelerar o tempo do discurso expressando-o por meio de uma linguagem em “peles de papel”, significa sustentar o jogo diplomático que estrutura uma negociação, frágil e temporária.

A narração sobre a origem da floresta, sobre a qual Kopenawa se debruça no início do livro, apresenta o mito da queda do céu - a partir dos primórdios de criação da floresta e de quando todos os seres partilhavam de uma condição humana —, se junta aos relatos dos recentes encontros com os brancos, atualizando o mito no contato com os brancos, com todo o estremecimento que essa aproximação significa para urihi.

A partir de sua vivência e leitura da cosmologia Yanomami, Bruce Albert aponta o posicionamento de Kopenawa a partir de alguns conceitos como território, meio ambiente e ecologia, alheios ao pensamento não dual dos indígenas, na emergência de um novo discurso político indígena, colocado em prática pelo xamã, de modo a assegurar a manutenção do que convencionamos designar como natureza e sua preservação e o 


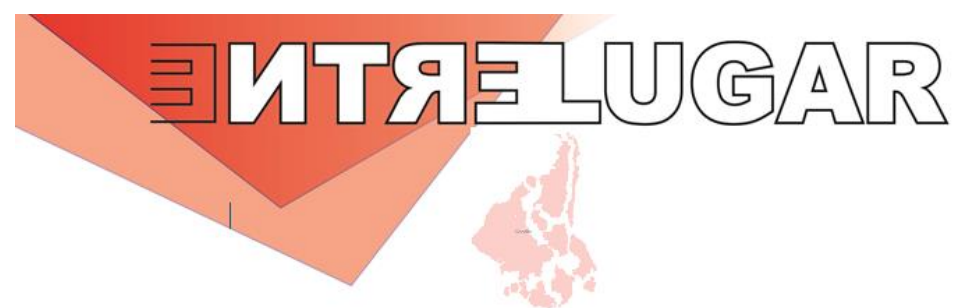

território e sua demarcação. Partimos desse discurso, colocado em prática pela militância e falas de Kopenawa, para o encontro com o filme tomado.

Tal discurso se encontra estruturando o papel do xamã e, igualmente, estrutura parte da escritura de Curadores da floresta, na medida em que o filme se estabelece a partir da apresentação do ritual e do entrecruzamento entre a importância da reunião que coloca em cena, juntamente com as palavras que acompanham a cerimônia. Então, voltemos ao filme e nos detenhamos em sua abertura.

Figura 13: Avião aterrissa em terras Yanomami.

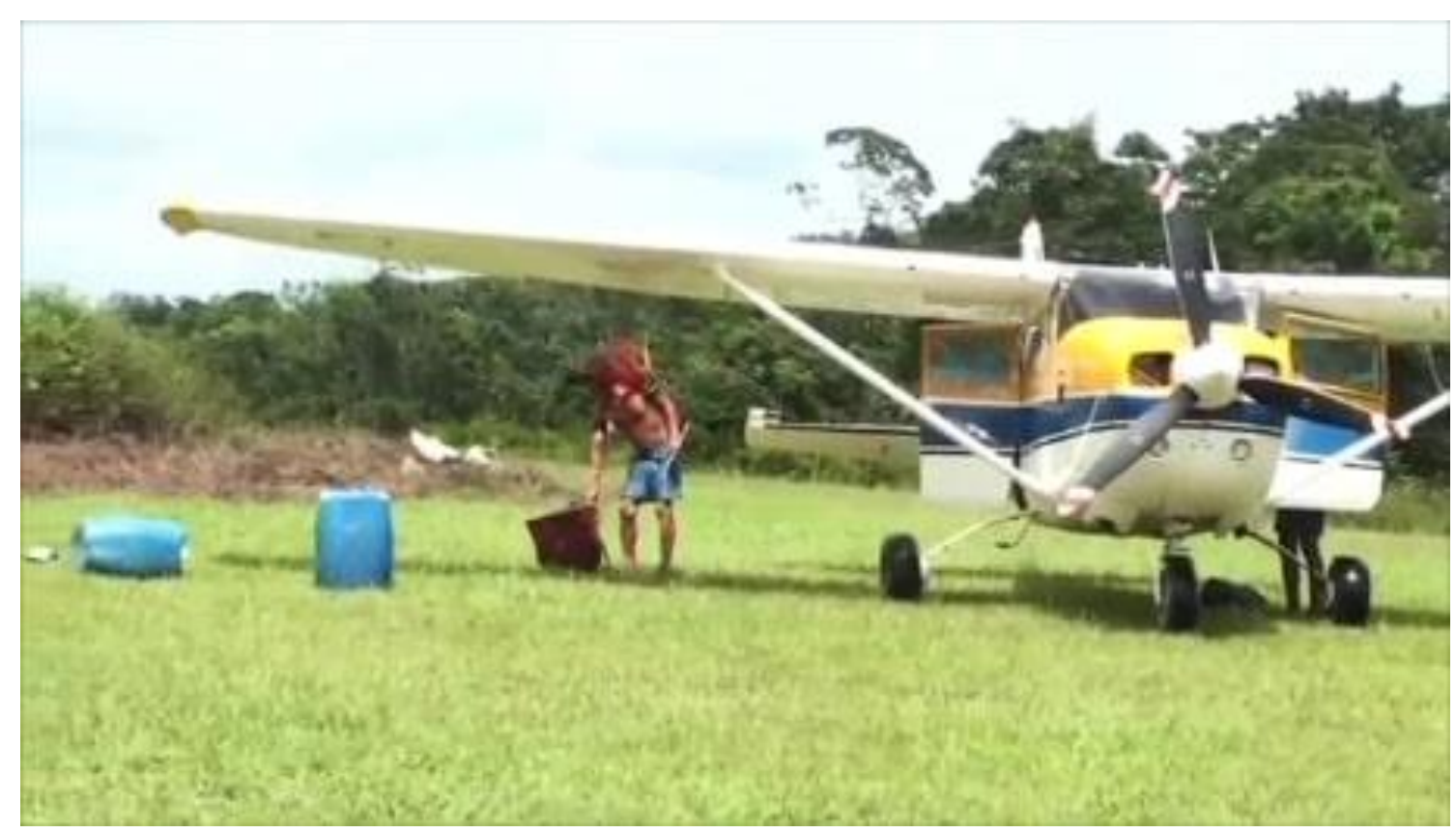

Fonte: "Urihi Haromatipe - Os curadores da terra floresta". Dir. Morzaniel Iramari, BRA (2014).

Nas primeiras tomadas, notam-se alguns indígenas, que posteriormente verifica-se serem xamãs de outras aldeias, desembarcando de um avião: os cuidadores da floresta se colocam em reunião. Nesses primeiros momentos eles são recebidos com a alimentação de uma bebida, possivelmente um fermentado de mandioca, ao que um dos indígenas diz “A barriga dos catitus não é grande”. Entrevê-se aí o momento prévio de uma cerimônia xamânica, em que farão descer os espíritos. 


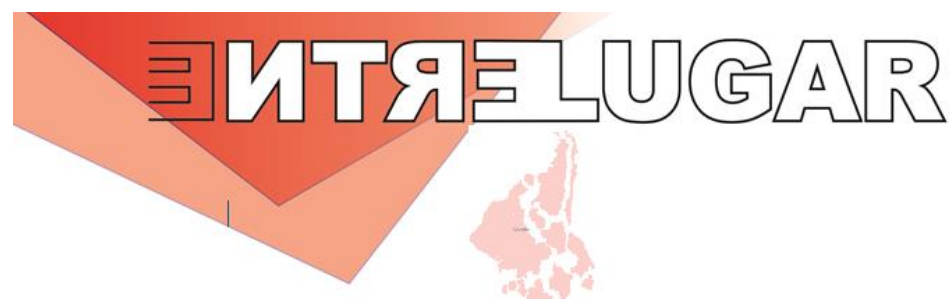

Nos momentos subsequentes, a retirada e a preparação da yakoana, substância extraída cuidadosamente da retirada e queimada das cascas da árvore yokoanape e transformada em pó para ser inalada pelos xamãs, são mostradas juntamente com uma narração que explicita a importância da substância para o ritual. Yakoana é o alimento dos xapiri, é através e por ela que os espíritos descem e os corpos podem cantar e dançar, e praticar a cura: "Quando a terra fica estranha, eles ajeitam”, o realizador indígena nos diz.

As cenas seguintes se detêm nas várias danças dos diversos xamãs do encontro, promovendo a duração que precisa acontecer. Há, praticamente, um planosequência para cada xamã diferente. O espaço da cena é construído a partir de uma duração, ${ }^{12}$ como um decurso, um decorrer, algo da ordem do ritual que precisa ser esperado, visto, sentido. Neste sentido, para abrigar aquilo que nos é invisível, a imagem precisa "demorar", para que a relação da imagem com o espectador produza uma transformação, como nos termos de Jean-Louis Comolli:

Transformação, então, e, para começar, transformação do lugar que é atribuído, destinado ao espectador e que o desenrolar do filme (é isso o que podemos chamar ficção) tem como missão — a palavra não é dogmática — transformar, mexer, deslocar. Esta duração é o que falta. Não é tanto as imagens que faltam, mas as imagens que duram é que faltam (COMOLLI, 2007, p. 128).

O espaço em cena em "Urihi Haromatipe" se faz sobretudo, assim, através de um tempo sentido na cena que dura, duração necessária para que o ritual nos atinja. Esperamos, nós espectadores, que o corpo se transforme, que se localize no espaço, que construa um certo lugar.

A sobreposição das imagens dos xamãs em contato com os xapiri e a narração são colocadas em convergência por meio da imagem no entrelaçamento do discurso do Yanomami e do próprio filme em seu propósito, quando a sua chamada se endereça aos brancos, algo próprio de seu discurso como líder índio. Os curadores da floresta são apresentados, nesse sentido, como os protetores dela, já que o universo sociocósmico

\footnotetext{
12 Da seguinte maneira, Jean-Louis Comolli pensa a importância das imagens que duram, cada vez mais raras, mas essenciais para o filme documentário, o filme dos homens ordinários: "A duração é o tempo para que alguma coisa se transforme e, antes de tudo, para que uma relação se estabeleça, se instale, se desenvolva entre sujeito (espectador) e o outro filmado (o que é preciso fazê-lo sentir; o que deve produzir afeto, emoção). " (COMOLLI, 2007, p. 128).
} 


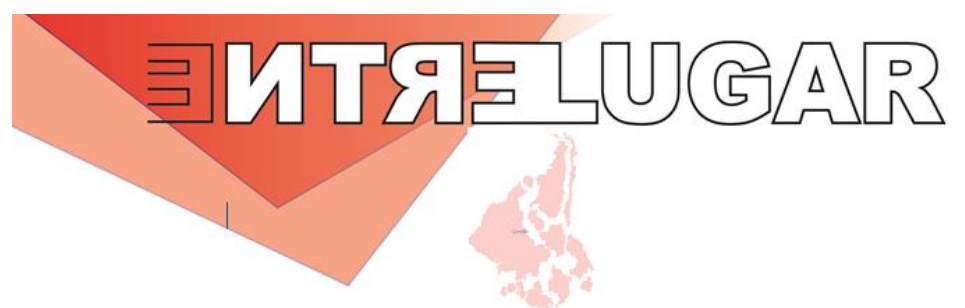

colocado em cena traz uma perspectiva ecológica pensada a partir de toda a preparação colocada em cena. Nesse movimento, ouvimos, em alguns momentos, a interpelação direta de uma voz, acompanhando as imagens do ritual xamânico, que sabemos ser provenientes das palavras de Kopenawa.

Figura 14: Indígena dança durante encontro entre xamãs.

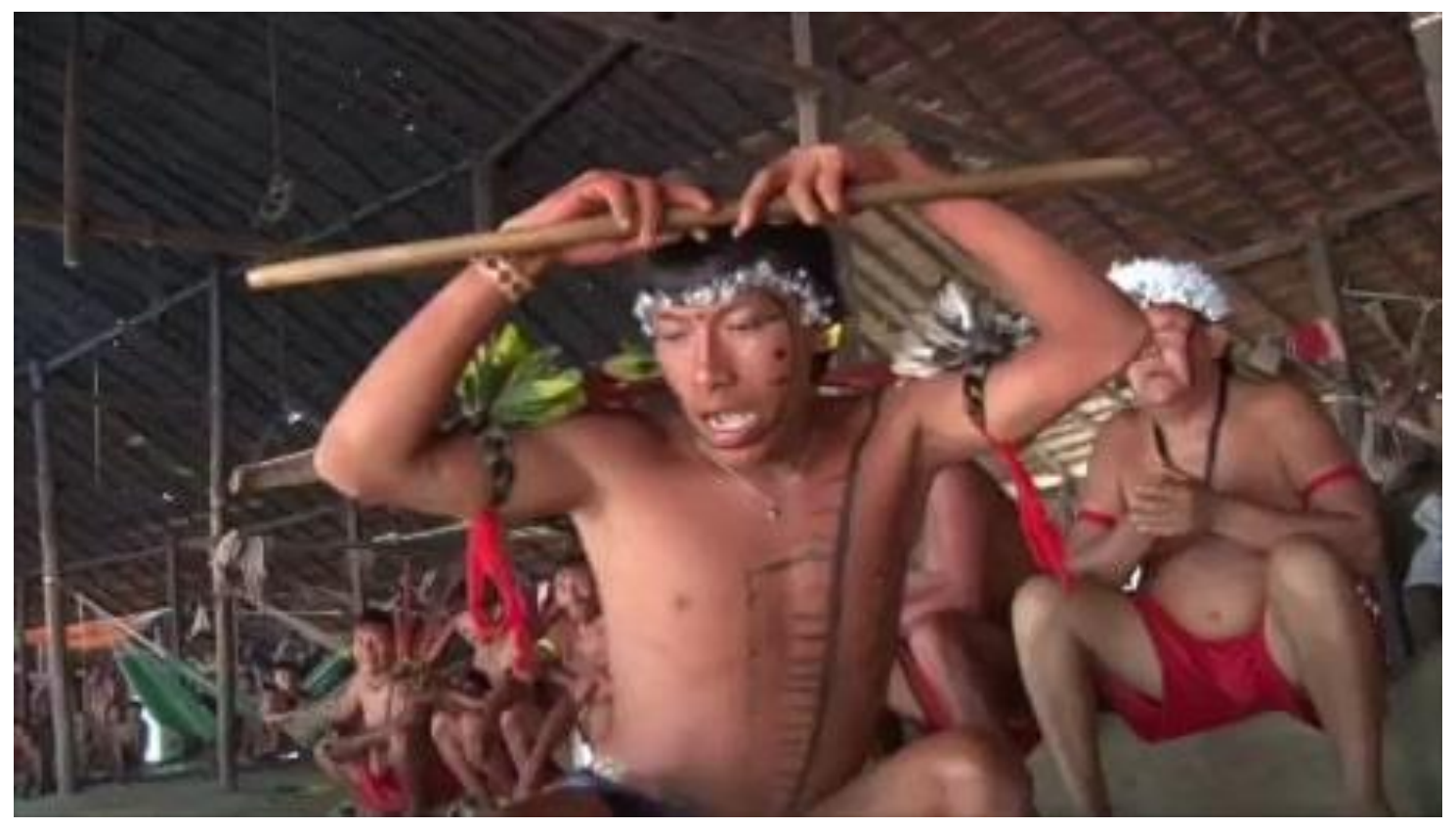

Fonte: "Urihi Haromatipe - Os curadores da terra floresta". Dir. Morzaniel Iramari, BRA (2014).

A partir do filme, o curador da floresta se dirige diretamente ao curador da cidade, em uma convocação, uma proposta cosmopolítica que coloca em suspense as diferenças conceituais acerca do mundo, de modo a garantir a sustentação dele, ao forjar uma forma de "encontro pragmático" (PINHEIRO DIAS; STENGERS, 2016). Davi, identificando a potência destrutiva e limitada do modo de olhar e viver a natureza da sociedade não indígena, convida a se esclarecer, a superar suas "palavras de esquecimento"; para que a floresta continue, para que a morada dos espíritos, e de todos os humanos, se sustente: para que o céu não desabe novamente. 


\section{CONSIDERAÇÕES FINAIS: ABERTURAS}

Uma certa noção de "natureza traduzida" parece ser colocada em prática, conformando a cena, a partir de discursos e agências que transgridem o mero registro do local habitado por personagens com traços identitários comuns, e que não se resume à tentativa de traduzir formalmente a experiência dos corpos em cena para os espectadores, em uma fé em que a experiência política do assistir deverá se realizar na tarefa do imaginar, do atravessamento por alteridades intangíveis concretamente, e, portanto, não exacerbadas pela imagem visível. O espaço do filme Urihi é como um imbricamento, atingido pelo fluxo do invisível que, no limite, influencia no que de fato vemos.

Em algumas de suas falas dirigidas aos brancos — assumidos como parte da audiência do filme - Kopenawa incorpora algumas de nossas abstrações conceituais, quando faz menção à "Terra", "planeta". Sua "política do cosmos"13 nos implica, nos interpela, e preenche o espaço do filme, compondo uma das experiências colocadas em cena. Tal política se presentifica em sua fala e potencializa um "mundo comum" conformado em cena. Tal mundo é formado, também, pelo que se abre à percepção por dimensões não táteis da imagem, que não se traduzem em termos visuais. Assistimos ao transe dos xamãs, mas não nos é alcançável a visão dos xapiri. Esse gesto de recuada frente a uma necessidade tátil para a experiência do espectador é como que um posicionamento potente. Sendo assim, o filme parece querer um diálogo, mas sem recair na necessidade ocidental de uma tradução formal, através de imagens manipuladas.

O espaço da cena de Urihi Haromatipe é performado através de palavras que de outros espaços veem, que se juntam em uma emergência discursiva atualizada. $O$ território do filme, trabalhado como resistência e instrumento de luta, é potencializado com a criação de um transespaço, feito de dos corpos que preenchem a cena da diferença, com cantos, danças e gestos que nos fazem imaginar o que os anima, incorporando fluxos invisíveis que incidem sobre eles e que, na demora de planos de ampla duração, dados a ver, insistem em sua manifestação, em sua incidência em cena, na devolução de um olhar para nós (Figura 3).

\footnotetext{
${ }^{13}$ Conforme a consideração de Viveiros de Castro (2004) sobre o pensamento ameríndio.
} 


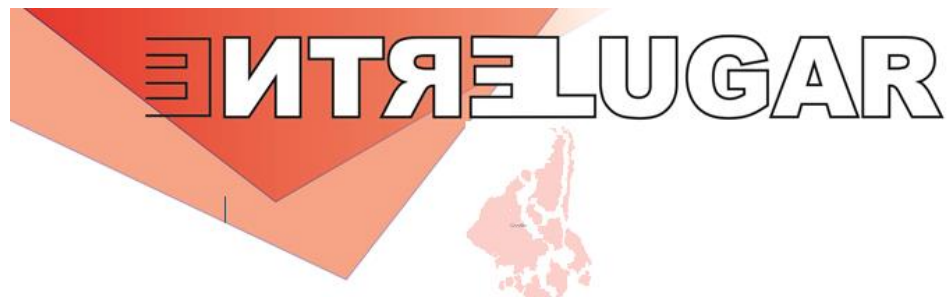

Figura 15: Dança de um xamã.

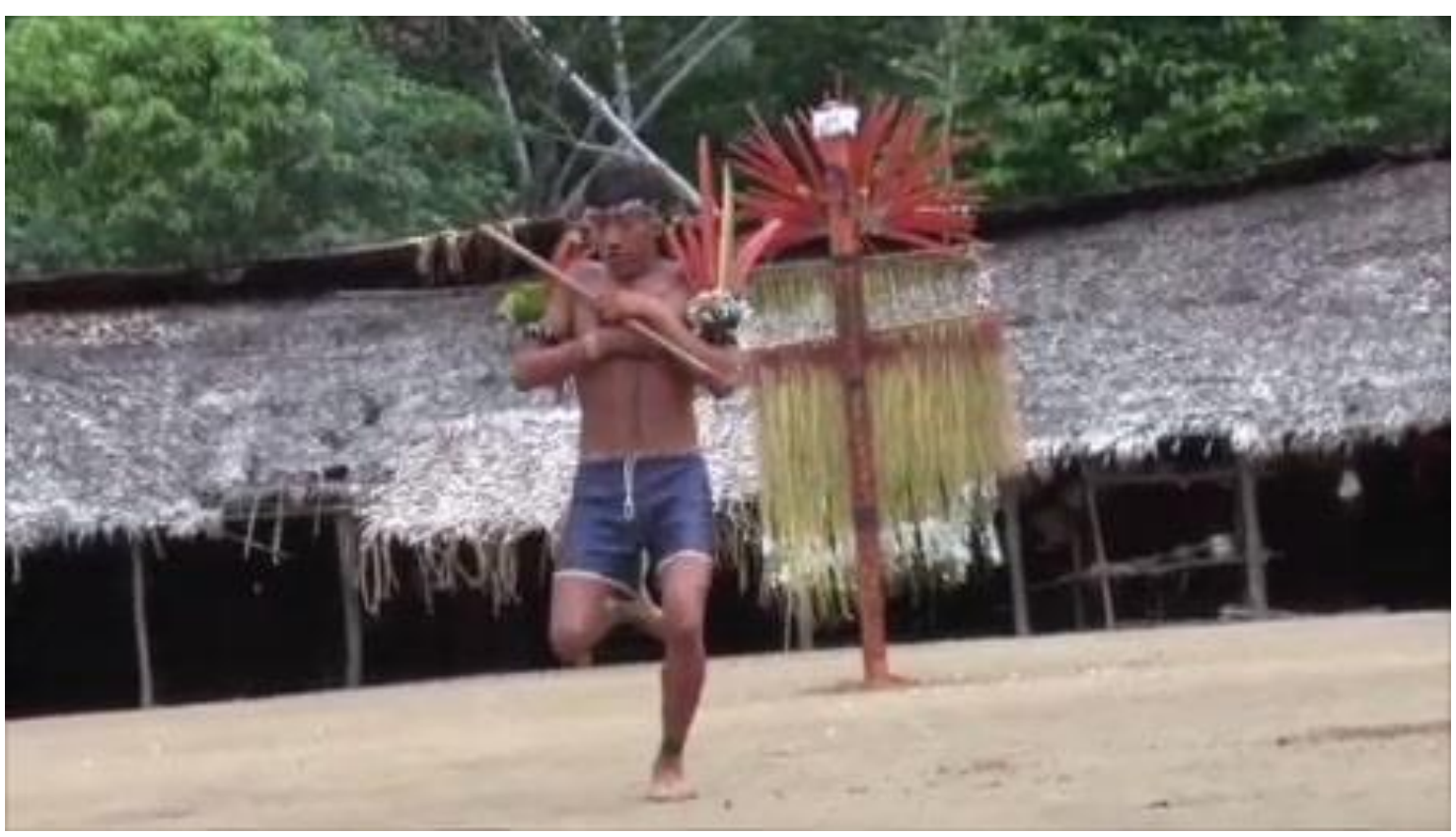

Fonte: "Urihi Haromatipe - Os curadores da terra floresta". Dir. Morzaniel Iramari, BRA (2014).

\section{REFERÊNCIAS BIBLIOGRÁFICAS}

ALBERT, Bruce. O ouro canibal e a queda do céu: uma crítica xamânica da economia política da natureza. In: ALBERT, B. e RAMOS, A (Org.). Pacificando o branco: cosmologias do contato Norte-Amazônico. São Paulo: Ed. Unesp/Imprensa oficial, 2002.

BRASIL, André. Ver por meio do invisível. O cinema como tradução xamânica. Novos estudos, CEBRAP. São Paulo, v. 35.03. Novembro, 2016. p. 125-146.

CASTRO, Eduardo Viveiros de. Perspectivismo e multinaturalismo na América indígena. O que nos faz pensar, $\mathrm{n}^{\mathrm{o}} 18$, setembro de 2004. Disponível em: http://oquenosfazpensar.fil.pucrio.br/import/pdf_articles/OQNFP_18_13_eduardo_vivei ros_de_castro.pdf.

COMOLLI, Jean-Louis. Os homens ordinários, a ficção documentária. 127-138. In: O Comum e a experiência da linguagem. SEDLMAYER, Sabrina; GUIMARÃES, César; OTTE, Georg (Org.). Belo Horizonte: Editora UFMG, 2007.

HISSA, Cássio Eduardo Viana Hissa. Território de diálogos possíveis. In: RIBEIRO, Maria Teresa Franco; MILANI, Carlos Roberto Sanchez (Org.). Compreendendo a complexidade socioespacial contemporânea. O território como categoria de diálogo interdisciplinar. Salvador: EDUFBA, 2009. p. 34-82.

KOPENAWA, D. e ALBERT, B. A queda do céu: palavras de um xamã Yanomami. Trad. Beatriz Perrone-Moisés. São Paulo: Cia. das Letras, 2015. 


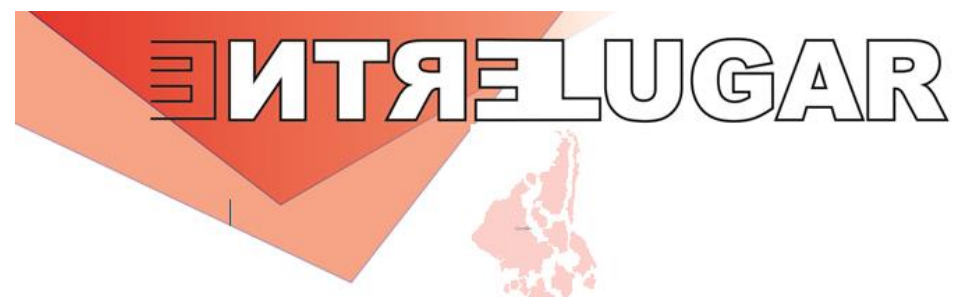

MARQUEZ, Renata. Arte e geografia. In: FREIRE-MEDEIROS, Bianca e COSTA, Maria Helena Braga e Vaz da (Org.). Imagens marginais. Natal: EdUFRN, 2006, p.1122.

MONDZAIN, Marie-José. Nada tudo Qualquer coisa Ou a arte das imagens como poder de transformação. In: SILVA, Rodrigo; NAZARÉ, Leonor (Org.). A república por vir. Arte, Política e Pensamento para o século XXI. Lisboa: Fundação Calouste Gulbenkian, 2011.

PINHEIRO DIAS, Jamille et al. Uma ciência triste é aquela em que não se dança. Conversações com Stengers. In: Revista de Antropologia, n. 59, v. 2, 155-186, ago. 2016.

SANTOS, Boaventura de Sousa. Para um novo senso comum: a ciência, o direito e a política na transição paradigmática / Boaventura de Sousa Santos. V. 1. A crítica da razão indolente: contra o desperdício da experiência. - 2. ed. - São Paulo: Cortez, 2000.

SANTOS, Milton. A natureza do espaço. Técnica e Tempo. Razão e Emoção. São Paulo: Editora Hucited, 1997. $2^{\mathrm{a}}$ edição.

SILVA, Rodrigo. A partilha do visível (pequeno excurso sobre a imagem). Cadernos PAR n. ${ }^{\circ} 4$ (Mar. 2011), p. 113-123.

STENGERS, Isabelle. A proposição cosmopolítica. In: Revista do Instituto de Estudos Brasileiros, n. 69, p. 442-464, abr. 2018.

SZTUTMAN, Renato. Cosmopolíticas transversais: a proposta de Stengers e o mundo ameríndio. (Palestra no Museu Nacional da Universidade Federal do Rio de Janeiro, em 29 de novembro de 2013. Mimeo.

Recebido para publicação em setembro de 2020. Aceito para publicação em março de 2020. 